\title{
Relaxor ceramics for multilayer capacitor application
}

\author{
P ROY-CHOWDHURY \\ Professor S D Chatterjee's Research Laboratory, 91 Ballygunge Place, Calcutta 700019, India
}

Abelract. Relaxor ferroelectrics, lead magnesium niobate (PMN) and lead zinc niobate (PZN) and their solid solution with lead titanate (PT) and barium titanate (BT) were studied. Lnlike lead magnesium niobate, the pyrooh lore-free material for lead zinc niobate could not be preprared by reaction between lead niobate and $\mathrm{ZnO}$ below $1000^{\circ} \mathrm{C}$. However, some improved composition was obtained when lead zinc niobate (85\%) and a mixlure of lead titanate $(10 \%)$ and barium titanate $(5 \%)$ sintered at $950^{\circ} \mathrm{C}$. XRD cxamination of the samples revealed that lead magnesium niobate prepared by us contained $9.9 \%$ pyrochlore phase, whereas the solid solution between $90 \%$ lead magnesium niobate and $10 \%$ Iead titanate was completely free from the same phase. The dielectric constant for PZN-PT-BT (85:10:5) ternary system was 4000 , whereas the sane for lead magnesium niobate and its solid solution with $10 \%$ lead titanate was 4100 and 6000 respectively. The comparatively low value obtained for PZN-PT-BT solid solution was probably dus to the presence of appreciable amount of pyrochlorc phese. The grain diameter for PMN and PMN-PT (90:10) solid solution was $1,37 \mu \mathrm{M}$ and $2 \cdot 34 \mu \mathrm{M}$ respectively.

Keywords. Relaxor ceramies; solid solution; multíayer apacitor; perovskite transducer.

\section{Inuradaction}

Relax or forroelectries has been developed because the $\mathrm{BaTiO}_{3}$-based capacitors, which are atill being used in the capacitor industry, require expensive and precious metal (Pd) for electroding. Replacing these with the highly fluxed compositions which densify at temperature $\left(<1000^{\circ} \mathrm{C}\right)$ with less expensive high silver-palladium alloy electrode is desirable. Relaxor ferroetectrics exhibit a frequency dispersion or dielectric medium i.e. the maximum dielectric constant increases and shifts to lower temperature as frequency is increased. This is because the statistical inhomogeneity in the distribution of B-site cations cteates microregions of varying transition temperature $T_{c}$ (Shrout et al 1964). It may be pointed out here that besides low firing temperature capability, the promising dielectrics should have a high dielectric constant $(>5000)$, low dielectric loss, good insulation resistance and good life performance. The relaxor ceramics of the type $\mathrm{Pb}\left(\mathrm{B}_{1 / 3}^{\prime} \mathrm{Nb}_{3 / 3}\right) \mathrm{O}_{3}$, where $\mathrm{B}^{\prime}=\mathrm{Mg}, \mathrm{Zn}, \mathrm{Ni}$, Fe, etc. and their solid solution with lead titanate or barium titanate near the morphotropic phase boundary exhibit very high dielectric constant and considerably large electrostrictional strains. This paper reports our preliminary results on the study of relaxor ferroelectrics, lead magnesium niobate and lead zinc niobate and their solid solution with lead titanate/barium titanate for possible capacitor application. Relaxor ceramics are advantageous over normal perovskite transducers in that they require no poling, show excellent positional reproducibility, have electrostrictive strains comparable to the best piezoelectric ceramics and also have low thermal coefficient. It is pertinent to mention here that the series of products made using multilayer ceramic technology started with three-layer quartz crystal package. It was followed sequentially by packages for diodes, transistors and multichip arrays. IBM used up to 123 chips/33 layer packages for the 3081 computer. Schwarta (1984) recently reviewed the technology used for making these substrates. 


\section{Experimental}

To avoid pyrochiore phase which develops during preparation, lead magnesium nicbate. $\mathrm{Pb}\left(\mathrm{Mg}_{1 / 3} \mathrm{Nb}_{2 i 3}\right) \mathrm{O}_{3}(\mathrm{PMN})$ was synthesized by reaction between lead niobate, $\mathrm{Pb}_{3} \mathrm{Nb}_{2} \mathrm{O}_{8}$ ( $\mathrm{PN}$ ) and $\mathrm{MgO}$ (1\% excess) (Guha and Anderson 1986) instead of using the conventional method (Swartz and Shrout 1982: Swartz et al 1984) where magnesium niobate $\mathrm{MgNb}_{2} \mathrm{O}_{6}$ was used to react with $\mathrm{PbO}$. Lead niobate was prepared by sintering $\mathrm{PbO}$ and $\mathrm{Nb}_{2} \mathrm{O}_{5}$ mixture in equimolar proportion for $9 \mathrm{~h}$ at $820^{\circ} \mathrm{C}$. Lead niobate and $\mathrm{MgO}$ were sintered in two steps for preparation of lead magnesium niobate. After sintering at $800^{\circ} \mathrm{C}$ in the first step, the dișks were crushed into powder and new disks (2.54 cm diam) prepared under $154.5 \mathrm{MPa}$ inch pressure by bydraulic press and sintered finaliy at $900^{\circ} \mathrm{C}$ for $6 \mathrm{~h}$. The solid solution between $90 \%$ lead magnesium niobate (PMN) and $10 \%$ lead titanate (PT) was similarly prepared by sintering the mixture (PN, $\mathrm{MgO}$ and $\mathrm{PT}$ in appropriate proportion) of the components in two separate steps, at $800^{\circ} \mathrm{C}$ and $950^{\circ} \mathrm{C}$ in the first and final steps respectively.

Unlike lead magnesium niobate, the preparation of pyrochlore-free material for lead zinc niobate, $\mathrm{Pb}\left(\mathrm{Zn}_{1 / 3} \mathrm{NB}_{2 / 3}\right) \mathrm{O}_{3}(\mathrm{PZN})$ by reaction between lead niobate and $\mathrm{ZnO}$ at $900^{\circ} \mathrm{C}$ was not possible. However, some improved composition was obtained by sintering between $85 \%$ lead zinc niobate (a mixture of $\mathrm{PN}$ and $\mathrm{ZnO}$ in appropriate proportion), and a mixture of $10 \%$ lead titanate and $5 \%$ barium titanate at $950{ }^{\circ} \mathrm{C}$ for $6 \mathrm{~h}$. Since firing temperatute of less than $1000^{\circ} \mathrm{C}$ was used, no atmospheric source of $\mathrm{PbO}$ was made use of.

$X$-ray diffraction of the compositions was examined using crushed ceramic disks. Latice constants were determined using a Philips X-ray diffractometer (model PW 1730 ) with nickel-fiitered $\mathrm{CuK}_{\alpha}$ radiation at a $2 \theta$ scanning rate $1^{\circ}$ per min. The angular range of $2 \theta$ covered was 20 to $80^{\circ}$. The peak angles were carefully indexed. The (001) and $(200) /(004)$ peaks of the perovskite phase were chosen to determitie the lattice constants.

Scanningelectron photomicrographs of the test samples were taken using a scanning electron microscope (Cambridge Stereoscan 150, Cambridge, England). As-fired samples were used for recording the pholomicrographs.

\section{Results and discussion}

Figure $1 A$ shows the XRD pattern of lead niobate prepared by sintering $P b O$ and $\mathrm{Nb}_{2} \mathrm{O}_{5}$ mixture (disks) in equimolar proportion at $820^{\circ} \mathrm{C}$. Complete solid solution with tetragonal symmetry ( $a_{0}$ and $c_{0}$ as $0.7557 \mathrm{~nm}$ and $1.087 \mathrm{~nm}$ respectively) comparable with the data $\left(a_{0}=0.753 \mathrm{~nm}\right.$ and $\left.c_{0}=1.082 \mathrm{~nm}\right)$ given for $\mathrm{PN}, \mathrm{Pb}_{3} \mathrm{Nb}_{2} \mathrm{O}_{3}$ in JCPDS card No $30-712$ was observed. PMN obtained by us contained some pyrochlore $\left(\mathrm{Pb}_{2} \mathrm{Nb}_{3} \mathrm{O}_{7}\right)$ phase which was revealed by XRD examination of the product (figure $1 \mathrm{~B}$ ). The volume fraction of the pyrochlore phase in the composition was estimated by the relation (Swartz and Shrout 1982; Goo et al 1986) given below

$$
\text { volume fraction of pyrochiore }=\frac{I_{P Y} \times 100}{I_{P E}+I_{P Y}}
$$

and was found to be $9.9 \%$. Here $I_{p_{Y}}$ is the intensity of the (222) pyrochlore X-ray peak and $I_{P E}$ the intensity of the (110) perovskite peak. However, the solid solution between 


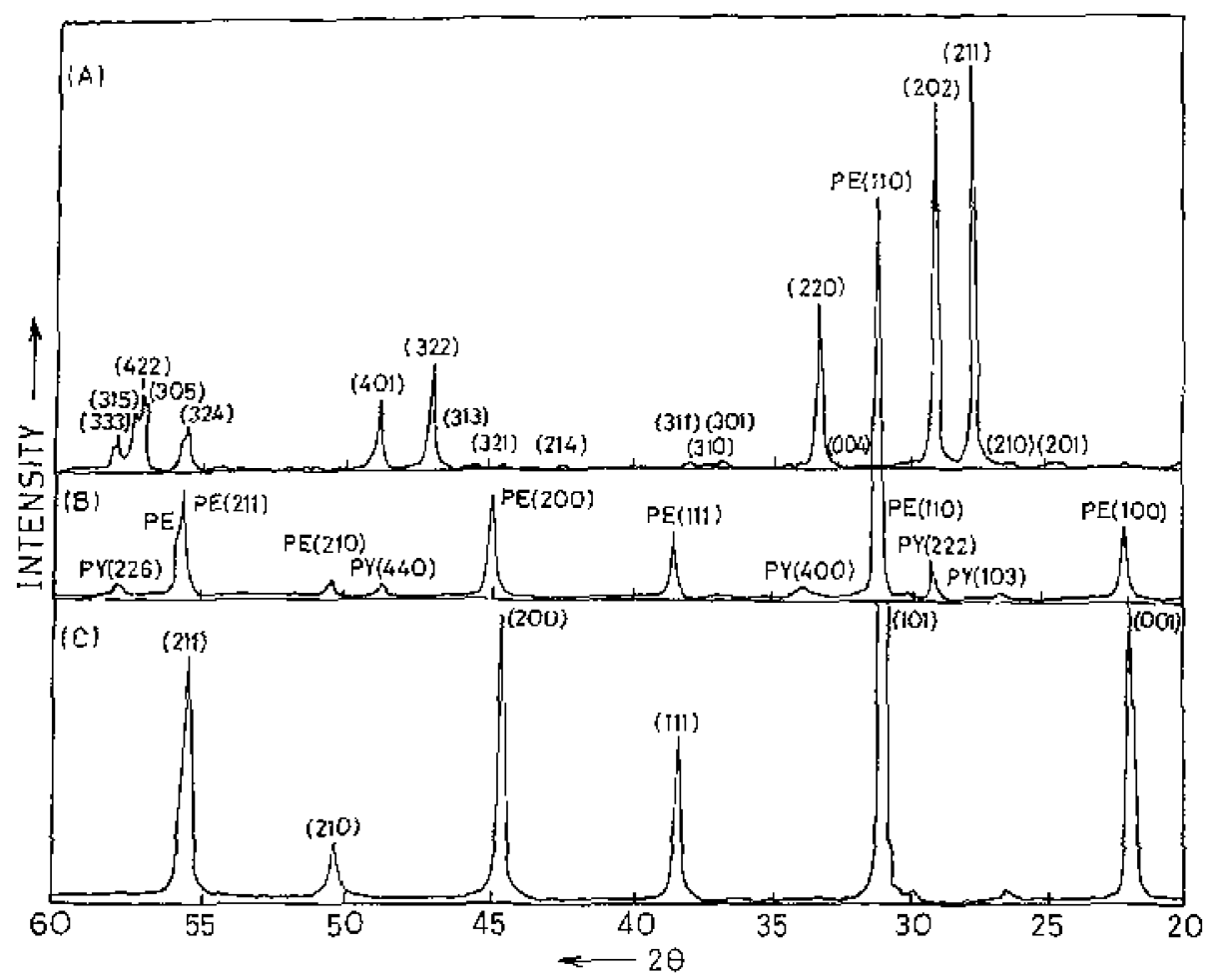

Figure 1. X-ray powder diltraction paltern of ( $A$ ) lead nipbate ( $P$ N), (B) lead magnesium niobatc ( $\mathrm{PMN}$ and $(\mathrm{C})$ solid solution of $90 \%$ lead magnesiun niobaie und $10 \%$ lezd vitanale (PMN-PT).

Table I. Lattice parameters for PN, PMN and PMN-PT (90:10) ceramics.

\begin{tabular}{|c|c|c|c|c|c|}
\hline Material & $D_{o}(0 m)$ & $c_{n}[n m)$ & $c_{n i} a_{s}$ & Structure & Synmetry \\
\hline $\mathrm{Pb}_{3} \mathrm{Nb}_{2} \mathrm{O}_{8}(\mathrm{PN})$ & 0.7557 & $1 \cdot 0876$ & 1459 & Perovskite & Totragonal \\
\hline \multirow[t]{2}{*}{$\mathrm{Pb}\left(\mathrm{Mg}_{1,3} \mathrm{Nb}_{2,3}\right) \mathrm{O}_{3}(\mathrm{PMN})$} & 0.40324 & - & - & Perovskite & Cubic \\
\hline & $1-0548$ & - & - & Pyrochlore & Cubic \\
\hline $90\left[\mathrm{~Pb}\left(\mathrm{Mg}_{1 ;}, \mathrm{Nb}_{2,3} \mathrm{OO}_{3}\right]-\right.$ & & & & & \\
\hline $10\left[\mathrm{PbTiO}_{3}\right][(\mathrm{PM} N-\mathrm{PT})$ & 0.4036 & 0.4050 & 1.003 & Perovikite & Tetrigonal \\
\hline
\end{tabular}

$90 \%$ PMN and $10 \%$ PT was found to be free from any pyrochlore phase (figure $1 \mathrm{C}$ ). Complete solid solution with tctragonal symmetry $\left(a_{0}=0.4036 \mathrm{~nm}\right.$ and $c_{0}=$ $0.4050 \mathrm{~nm}$ ) was observed. Our results of lattice parameters are summarized in table 1. The Curie temperature $T_{r}$ of the solid solution PMN-PT was measured as $53^{\circ} \mathrm{C}$ which was above the room temperature. The $T_{r}$ of PMN was much below the room temperature. As expected, since the Curie temperature for PMN lay below the room temperature, the XRD mcasurement taket at room temperature indicated that the symmetry was cubic. whcreas in the case of the solid solution PMN PT, where $T_{r}$ was above room temperature, the symnetry was tetragonal (table i). The structural analysis results of the solid solution PZN-PT BT $(85: 10: 5)$ will be communicated elsewhere. 

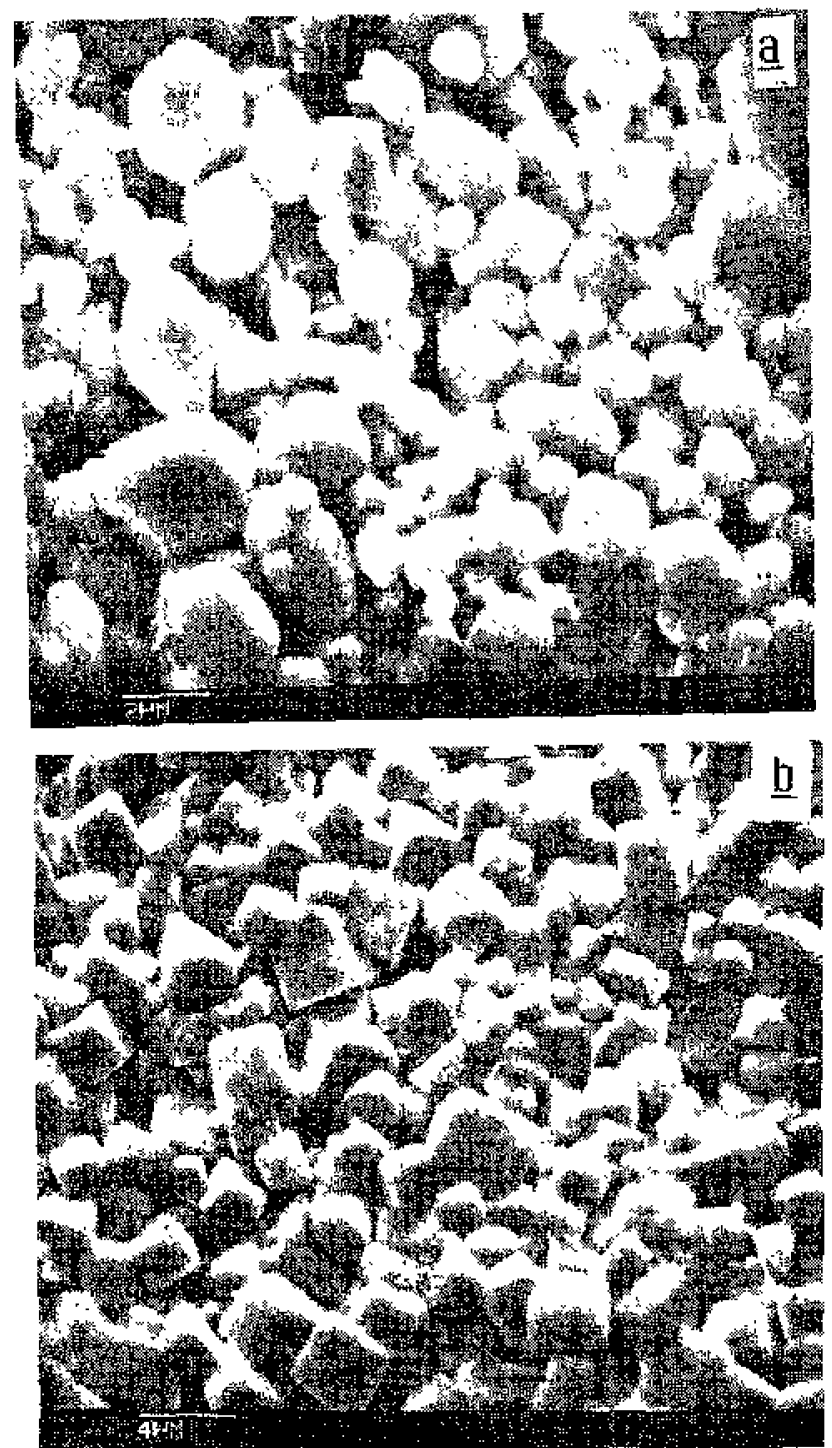

Figure 2. Scantning electron micrographs of the as-fired surfaces of (a) Lead magnesium niobate (PMN) and (b) solid solution of $90 \%$ lead magnesium niobate and $10 \%$ of lead titanate (PMN-PT).

The value of $\varepsilon_{r}$ of PMN measured at $1 \mathrm{kHz}$ was 4100 (reported value $\sim 5000$ ) which was somewhat lower because of the presence of pyrochlore phase. $\varepsilon_{T}$ of the materials was reduced drastically due to the presence of pyrochlore phase which developed during preparation. In the case of the solid solution PMN-PT, the dielectric constant was lound to increase to 6000 (reported value being 7000 (Uchino et al 19811). Further in the case of PZN-PT-BT $(85: 10: 5)$ ternary system, the dielectric constant was 4000 which was very low compared to the reported value (15000) (Halliyal et al 1987).

The typical photomicrographs of the as-fired surfaces for $P M N$ and its solid solution with $10 \%$ PT are shown in figure 2 ( $\mathrm{A}$ and $\mathrm{B}$ ). There was a wide distribution of grain 
sizes in both cases. The average grain diameter was determined by the linear intercept method (Fullman 1953) which was 1.37 $\mu \mathrm{M}$ and $2.34 \mu \mathrm{M}$ for PMN and PMN-PT solid solution respectively. $A_{n}$ two-fold increase of grain size was observed in the case of PMN-PT solution.

\section{Conclusion}

The relaxor ceramic PMN prepared by the reaction between lead niobate and $\mathrm{MgO}$ below $1000^{\circ} \mathrm{C}$ showed promise for use in multilayer capacitors with high silverpalladium electrodes. The solid solution between $90 \%$ PMN and $10 \%$ PT showed further improvement of dielectric constant (from 4100 to 6000). The Curie temperature of PMN--PT solid solution was $53^{\circ} \mathrm{C}$, whereas the same for PMN was much below the room temperature. The preparation of pyrochlore-free material for PZN by reaction between lead niobate and $\mathrm{ZnO}$ was not achieved, but the stabilization of the perovskite phase 10 some extent was done with the addition of $10 \%$ lead titanate and $5 \%$ barium titanate. The dielectric constant of the composition obtained was 4000 . The symmetry for PMN and its solid solution with $10 \%$ PT measured at room temperature was cubic and tetragonal as the Curie temperature for the two compositions was below and above the room temperature respectively.

\section{References}

Fuflman R L 1953 Trans. AIME 197447

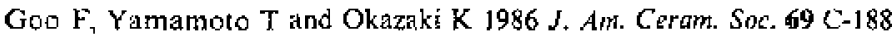

Guha J P and Anderson H U $1986 \mathrm{~J}$. Am. Ceram. Soc. $69 \mathrm{C}-287$

Halliyal A, Kumar U, Newnham R E and Cross L E $1987 \mathrm{~J}$. Am. Ceram. Soc. 70119

Schwarti B J 1984 J. Phys. Chem. Solids 45105

Shrout T R, Swartz S L and Haun M J 1964 Am. Ceram. Soc. Bthl. 63808

Swartz S L and Shrout T R 1982 Mater. Res. Buill. 171243

Swartz S L, Shrout T R. Schultze W A and Cross L E 1984 J. Am. Ceram. Sic. 67311

Uehino K, Nemura S, Cross L E, Newnitam R E and Jang S J 1981, J. Mater. Sci. 16569 